\title{
Select papers from the 2016 Denver X-ray Conference in Powder Diffraction Journal
}

The 2016 Denver X-ray Conference (DXC) was held in Rosemont, Illinois USA, just outside of Chicago. There were over 500 attendees at this first mid-western US DXC meeting, and included over 250 technical presentations. As part of DXC, the conference proceedings are published in Advances in $X$-ray Analysis ( $A X A$ ) with the 60th $A X A$ volume being published for DXC 2016. Today all of the DXC conference proceedings are available on CD-ROM, with Volumes 40-57 ( 1000 papers) available as open access on the ICDD web (http://www.icdd.com/resources/axasearch/search_ based_on_vol.asp).

Selected papers to be published in AXA Volume 60 have been included in this issue of Powder Diffraction. These papers were chosen by the reviewers and the DXC Organizing Committee, highlighting current studies in materials analysis and analytical methods using $\mathrm{X}, \gamma$, electron, and neutron radiations. These $A X A$ papers are intended to broaden the scope of information provided to readers of $P D J$.

The titles of these papers are:

NEW NEUTRON TIME-OF-FLIGHT (TOF) CAPABILITY IN PDF-4+ RELATIONAL DATABASES: DIGITIZED DIFFRACTION PATTERNS AND I/I $\mathrm{I}_{\mathrm{C}}$ FOR QUANTITATIVE PHASES ANALYSIS (Faber et al.)

POWDER XRD AND TEM STUDY ON CRYSTAL STRUCTURE AND INTERSTRATIFICATION OF ZnCHLORITE (BAILEYCHLORE) (Xu et al.)

SINGLE CRYSTAL STRUCTURE ANALYSIS OF DESIGNER DRUGS CIRCULATING IN THE JAPANESE DRUG MARKET BY THE SYNCHROTRON RADIATION X-RAY DIFFRACTION (Hashimoto et al.)
MATERIALS ASSURANCE THROUGH ORTHOGONAL MATERIALS MEASUREMENTS: X-RAY FLUORESCENCE ASPECTS (Rodriguez et al.)

A 2D PIXEL DETECTOR FOR VERY HIGH-RATE XAND GAMMA-RAY SPECTROSCOPY AND IMAGING (Nygard et al.)

This year's 66th Denver X-ray Conference (31 July-4 August 2017) will be held in Big Sky, Montana, USA. In the tradition of DXC meetings the conference will start with 2 days of workshops covering beginning, intermediate, and advanced topics, and will also have evening poster sessions, a plenary session with the theme Inspecting the Infrastructure - Safeguarding with X-rays, and 3 days of technical sessions. DXC also provides an excellent opportunity to visit with instrument, software, and component exhibitors where individuals can see equipment and software demonstrations as well as ask questions specific to analysis needs. Check out the meeting program at the conference web site http://www.dxcicdd.com/17/program.htm and the program is also included in this June issue of Powder Diffraction.

A visit to Big Sky also includes close proximity (50 miles or $80 \mathrm{kms}$ ) to Yellowstone National Park. A beautiful location with wildlife and natural settings are a wonder to behold. I look forward to seeing everyone in Big Sky!

For the DXC Organizing Committee

Tom Blanton Executive Director and Principal Scientist, International Centre for Diffraction Data 